\title{
PERKEMBANGAN POPULASI KUTU PERISAI AULACASPIS TEGALENSIS ZEHNTNER (HOMOPTERA: DIASPIDIDAE) DAN PENGARUH TINGKAT SERANGANNYA TERHADAP PENURUNAN HASIL TEBU DI PT GUNUNG MADU PLANTATIONS, LAMPUNG TENGAH
}

\author{
Sunaryo $^{1}$ dan Rosma Hasibuan ${ }^{2}$
}

\begin{abstract}
Population development of a scale insect Aulacaspis tegalensis Zehntner (Homoptera: Diaspididae) and effect of its infestation on sugarcane yield loss in PT Gunung Madu Plantations, Central Lampung. Sugarcane scale insect, Aulacaspis tegalensis, is a new major pest of sugarcane in PT Gunung Madu Plantations (GMP). A survey was conducted at the experimental station of the Research and Development Division of PT GMP to investigate the population growth of the pest and effects of their infestation on sugarcane production. The first study indicated that the population of the pest started to grow when the host plants were at the age of 8 months and reached a peak (300 individuals/stem) on mature sugarcane plants (11 month old). A low population of the pest at younger sugarcane plants might be due to the fact that during their first seven months of growth, sugarcane plants had no stem or even if they had, the leaf sheaths were still closedly intact to the stem, while the scale insects could live and survive optimally at the internodes under the leaf sheaths. The second study showed that the first pest outbreak occurred in 2000 which covered 162.27 ha of sugarcane fields. In the year of 2001, the infested area increased significantly (up to $1157.93 \mathrm{ha}$ ). In addition, the effect of the scale insect infestation caused an enormous yield loss. The losses could be expressed as the reductions in: stem weight, pol (polarisation, sucrose content), brix (total soluble solids), and sugar contents.
\end{abstract}

\section{Kata kunci: sugarcane scale insect, Aulacaspis tegalensis, population growth, infestation, yiled losses}

\section{PENDAHULUAN}

Spesies kutu perisai yang menyerang tanaman tebu di PT Gunung Madu Plantations, Lampung Tengah pada saat ini diduga adalah Aulacaspis tegalensis Zehntner (Homoptera: Diaspididae) (Tim R\&D PT GMP, 2001). Pada tahun 1898, kutu perisai yang ada di Pulau Jawa diidentifikasi sebagai Chionapsis tegalensis, namun pada tahun 1921 Ferris (di Taiwan) mengusulkan nama genus kutu perisai tersebut menjadi Aulacaspis dan hal ini diperkuat oleh Scott (di Mauritius) pada tahun 1952. Sampai sekarang, nama genus kutu perisai tersebut yang diterima adalah Aulacaspis (Rao \& Sankaran, 1969). Di Pulau Jawa, ada dua spesies kutu perisai yang menyerang tanaman tebu yaitu $A$. tegalensis dan $A$. madiunensis (Samoedi, 1993; Hill \& Waller, 1994). Kedua spesies tersebut mempunyai ciri morfologi yang mirip satu sama lain, tetapi tingkat serangan yang ditimbulkan kedua spesies tersebut berbeda, yaitu tingkat serangan yang ditimbulkan oleh kutu perisai A. tegalensis lebih berat dari kutu $A$. madiunensis. Persebaran A. tegalensis pada pertanaman tebu cukup luas meliputi Indonesia (Jawa, Sumatra), Malaysia, Filippina, Taiwan, Hawai, Afrika
Selatan, Madagaskar, Mauritius, dan Kenya (Box, 1950; Long \& Hensley, 1972).

Kutu perisai $A$. tegalensis mempunyai ukuran tubuh yang tergolong kecil (panjang tubuh dewasa hanya $1,04 \mathrm{~mm}$ ). Kutu tinggal dalam perisai (panjang 2,90 $\mathrm{mm}$ ) yang terbuat dari bahan lilin batang tebu dan bahan sekresi kutu tersebut. Kutu betina mengalami pergantian kulit sebanyak dua kali, sedangkan yang jantan empat kali (Rao \& Sankaran, 1969; Williams, 1970).

Imago kutu perisai dapat menghasilkan telur sebanyak 150 sampai 250 butir telur yang diletakkan di dalam perisai. Setelah menetas, nimfa instar-1 (panjang 0,26 mm) keluar dari perisai induknya melalui bagian tepi bawah perisai. Perisai yang pernah mengeluarkan nimfa terlihat tidak rusak tetapi menjadi lebih mudah terbuka. Nimfa instar-1 bergerak aktif beberapa waktu, terutama di sekitar induknya dan kemudian berdiam diri dan hidup dengan cara menusukkan alat mulutnya (stylet) ke jaringan tanaman tebu. Nimfa instar-1 merupakan satusatunya fase yang aktif sedangkan fase lain tidak dapat berpindah (sedentary) (Rao \& Sankaran, 1969).

Khusus di PT GMP, keberadaan hama kutu ini telah lama diketahui dan dikenal sebagai hama

\footnotetext{
${ }^{1}$ Staf Riset dan Pengembangan PT Gunung Madu Plantations, Lampung Tengah

${ }^{2}$ Dosen Jurusan Proteksi Tanaman Fakultas Pertanian, Universitas Lampung
} 
minor (karena populasi dan tingkat serangannya selalu rendah). Namun akhir-akhir ini, serangan hama kutu perisai tersebut secara konsisten semakin meningkat dan meluas hingga menyerang semua varietas yang ditanam di pertanaman tebu GMP (Tim R\&D PT GMP, 2001). Percobaan ini bertujuan untuk mengetahui perkembangan populasi kutu perisai $A$. tegalensis pada pertanaman tebu dan pengaruh tingkat serangan hama tersebut terhadap penurunan hasil tanaman tebu di PT GMP.

\section{METODE PENELITIAN}

Penelitian terdiri atas dua percobaan yaitu: (1) perkembangan populasi kutu perisai A. tegalensis pada tanaman tebu di lapangan, dan (2) pengaruh intensitas serangan kutu perisai terhadap kehilangan hasil tanaman tebu. Penelitian dilaksanakan di kebun percobaan Research and Development (R \& D) PT Gunung Madu Plantations Terusan Nunyai, Lampung Tengah mulai bulan Juni 2001 sampai dengan Juni 2002.

\section{Perkembangan Populasi}

Pengamatan populasi kutu perisai dilakukan dengan metode survei pada salah satu varietas yang ditanam di PT GMP yaitu GM 21. Pengamatan dilakukan pada lima petak tanaman tebu yang terserang hama kutu perisai seluas $5 \times 3,5 \mathrm{~m}$ Kepadatan populasi diamati dan dihitung secara rutin setiap bulan mulai tanaman berumur 2 bulan (Agustus 2001) sampai menjelang panen (umur 12 bulan, Juni 2002). Pengamatan populasi dilakukan dengan cara memeriksa setiap ruas batang tebu yang terserang dan menghitung jumlah kutu perisai pada setiap batang. Data yang terkumpul disusun secara runtun waktu (time series) dan digambarkan dalam bentuk grafik.

\section{Tingkat Serangan}

Bagian tanaman tebu yang dipanen adalah batang (bagian tanaman yang disukai oleh hama kutu perisai), sehingga sasaran pengamatan penurunan hasil akibat serangan hama kutu perisai adalah batang tebu. Percobaan pengaruh serangan hama kutu perisai terhadap penurunan hasil tanaman tebu dilakukan pada lima petak tanaman tebu yang terserang hama kutu perisai pada kebun percobaan $\mathrm{R}$ \& D PT GMP. Untuk menentukan tingkat serangan, kriteria serangan ditetapkan berdasarkan proporsi ruas batang yang terserang hama kutu perisai. Tingkat serangan dikelompokkan menjadi tiga kategori, yaitu batang terserang ringan (1 -- 25\% ruas terserang), batang terserang sedang (26 -- 50\% ruas terserang), dan batang terserang berat (lebih dari $50 \%$ ruas terserang) (Tabel 1).

Tabel 1. Kriteria tingkat serangan hama kutu perisai A. tegalensis pada tanaman tebu di PT GMP

\begin{tabular}{cc}
\hline Kategori serangan & Ruas batang terserang (\%) \\
\hline Ringan & $1-25$ \\
Sedang & $26-50$ \\
Berat & $>50$ \\
\hline
\end{tabular}

Serangan hama kutu perisai dapat menurunkan hasil berupa bobot (kuantitas) dan mutu (kualitas) produksi tanaman tebu. Kuantitas hasil dapat ditentukan dari indikator bobot batang, sedangkan kualitas hasil ditentukan oleh tiga indikator yaitu: pol, brix, dan rendemen. Secara spesifik, pol dan brix digunakan di pabrik gula sebagai indikator untuk menentukan kualitas nira (juice) ekstrak (cairan) tanaman tebu. Brix adalah istilah yang digunakan untuk menyatakan jumlah total padatan terlarut (total soluble solids) pada larutan gula dengan menggunakan alat refraktometer pada $20{ }^{\circ} \mathrm{C}$ yang dilengkapi dengan timbangan. Istilah pol menunjukkan kandungan sukrosa pada cairan gula yang ditentukan dengan metode polarisasi (polarisation). Rendemen adalah kandungan gula tanaman tebu. Sebagai pembanding, data keempat indikator tersebut juga diukur pada batang sehat.

\section{HASIL DAN PEMBAHASAN}

\section{Perkembangan Populasi}

Hasil pengamatan menunjukkan bahwa perkembangan populasi kutu perisai $A$. tegalensis pada tanaman tebu varietas GM 21 (salah satu varietas yang sering ditanam di PT GMP) mulai meningkat pada tanaman berumur 8 bulan dan mencapai puncaknya pada tanaman berumur 11 bulan (Gambar 1). Pada tanaman berumur 2 bulan, ratarata kepadatan populasi kutu perisai hanya 


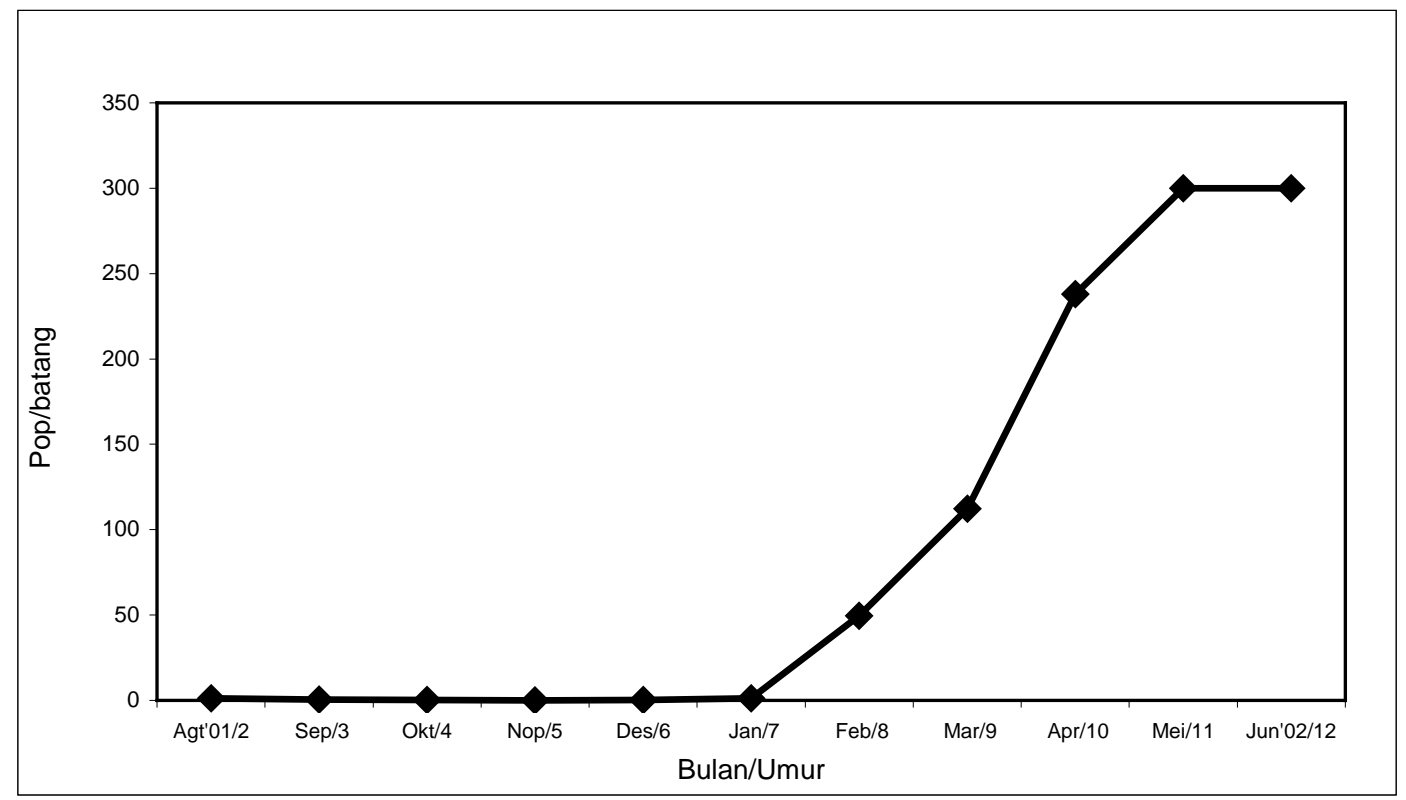

Gambar 1. Perkembangan populasi kutu perisai A. tegalensis pada tanaman tebu varietas GM21 di PT GMP

1,3 ekor/batang dan kondisi populasi rendah ini tetap bertahan sampai tanaman berumur 7 bulan. Namun, sewaktu tanaman berumur 8 bulan, populasi kutu meningkat menjadi 49,6 ekor/batang dan terus meningkat hingga mencapai puncaknya 300 ekor/batang pada saat tanaman berumur 11 bulan (tanaman mulai masak). Rata-rata umur tanaman tebu siap panen adalah 12 bulan. Secara umum, rata-rata kepadatan populasi selama musim tanaman sekitar 100 ekor/batang.

Hasil percobaan di atas menunjukkan bahwa tanaman tebu yang masih muda (kurang dari 7 bulan) kurang disukai oleh hama kutu perisai dibandingkan dengan tanaman tebu yang umurnya lebih tua (di atas 7 bulan). Pola perkembangan populasi kutu perisai yang sedemikian kemungkinan berhubungan erat dengan perilaku hidup dan makan kutu yang memerlukan kondisi pertumbuhan tanaman tebu yang spesifik. Semua fase pertumbuhan kutu perisai (kecuali instar-1) bersifat menetap (sedentary) dan hidup dengan cara menusukkan stiletnya (alat mulut) ke dalam jaringan batang untuk mengisap cairan nutrisi tanaman tebu (Rao \& Sankaran, 1969) Oleh karena itu, bagian tanaman tebu yang disukai oleh kutu perisai adalah ruas batang tebu. Pada kenyataannya, ruas batang tanaman tebu yang masih muda (kurang dari 7 bulan) belum tumbuh penuh, namun walaupun batang tebu sudah mulai terbentuk, pada saat tersebut pelepah daun masih melekat kuat pada batangnya sehingga kutu perisai mengalami kesulitan untuk mencapai ruas batang tempat mereka hidup dan berkembang biak. Sebaliknya pada saat tanaman sudah mulai tua (lebih dari 8 bulan), sebagian besar pelepah daun (terutama yang di bagian pangkal batang) sudah mulai merenggang sehingga kutu perisai dapat mencapai ruas batang tebu (terutama di sela pelepah daun dan batang) dengan mudah. Pelepah daun dapat berfungsi untuk melindungi kutu dari ancaman faktor luar (musuh alami dan kondisi cuaca buruk).

\section{Tingkat Serangan}

Areal pertanaman tebu PT GMP yang terserang hama kutu perisai $A$. tegalensis setiap tahun cenderung semakin meningkat. Pada tahun 2000, luas petak pertanaman tebu yang terserang hama tersebut mencapai 162,37 ha, di antaranya yang terserang berat (bagian batang terserang > 50\%) seluas 5,26 ha $(3,24 \%)$. Namun pada tahun 2001, populasi kutu perisai telah berkembang dengan pesat

\footnotetext{
${ }^{1}$ Staf Riset dan Pengembangan PT Gunung Madu Plantations, Lampung Tengah

${ }^{2}$ Dosen Jurusan Proteksi Tanaman Fakultas Pertanian, Universitas Lampung
} 
dan menyerang hampir seluruh petak pertanaman tebu PT GMP. Luas serangan pada tahun 2001 mencapai 1157,95 ha (peningkatan tujuh kali lipat dibandingkan dengan tahun sebelumnya) disertai dengan peningkatan batang yang terserang berat yang mencapai 18,08\% (209,30 ha) (Tabel 2). Hal ini menunjukkan bahwa hama kutu perisai yang selama ini dianggap hama minor, belakangan telah berubah menjadi hama penting.
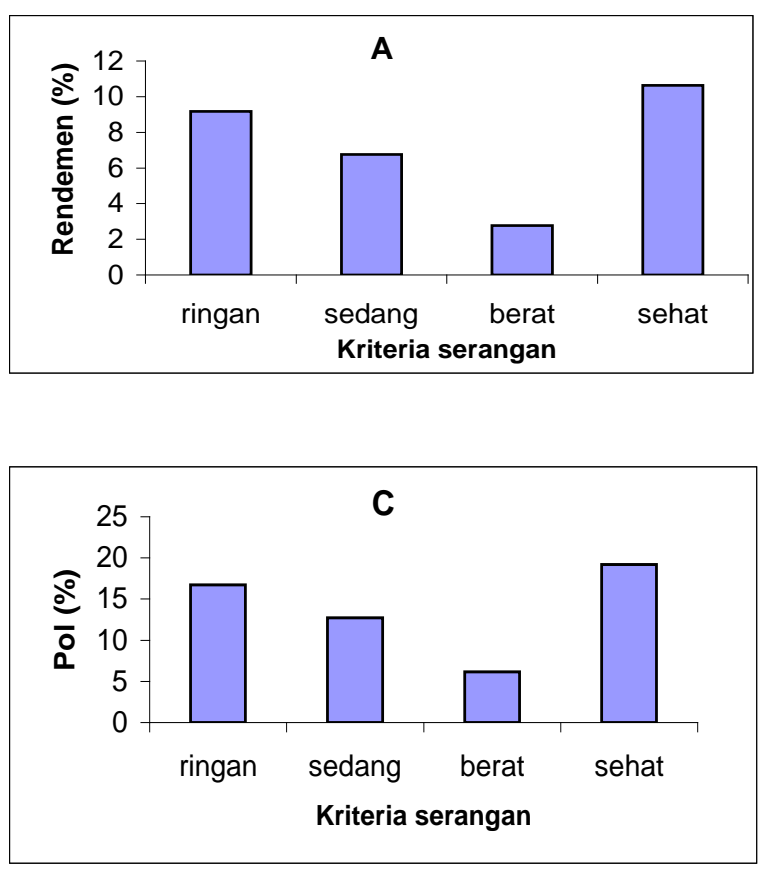

Tabel 2. Luas serangan hama kutu perisai A. tegalensis pada tanaman tebu di PT GMP, Lampung Tengah

\begin{tabular}{ccc}
\hline Tahun & $\begin{array}{c}\text { Luas serangan } \\
\text { total (ha) }\end{array}$ & $\begin{array}{c}\text { Persentase } \\
\text { terserang berat }\end{array}$ \\
\hline 2000 & 162,37 & $3,24 \%$ (5,26 ha) \\
2001 & 1157,95 & $18,08 \%$ (209,30 ha) \\
\hline
\end{tabular}
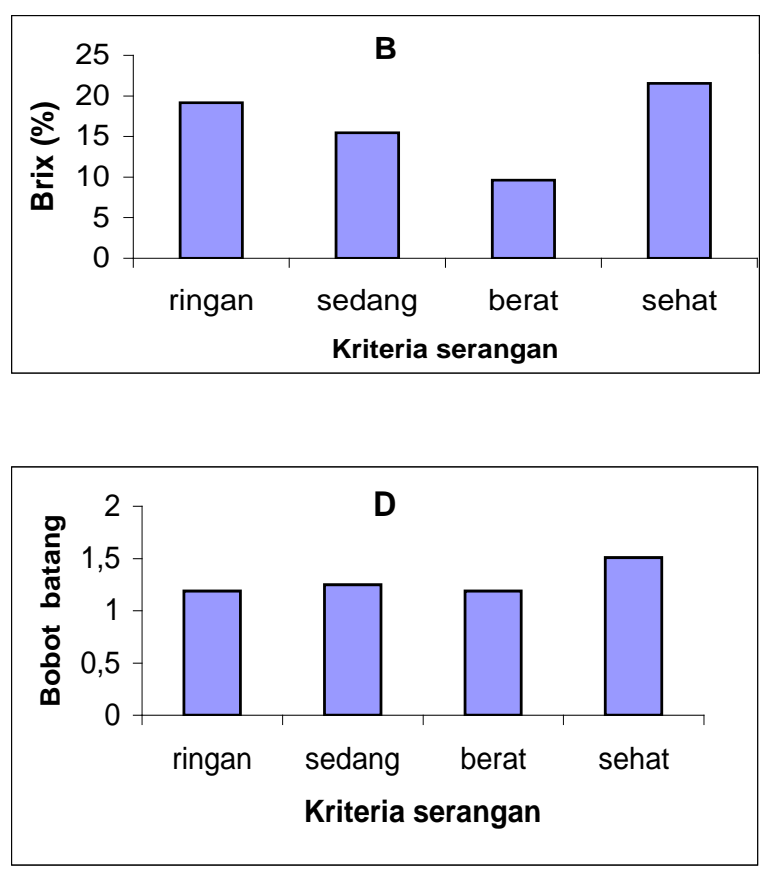

Gambar 2. Histogram tingkat serangan hama kutu perisai A. tegalensis (dengan kriteria ringan, sedang, berat, dan sehat) pada indikator hasil tanaman tebu ( Rendemen = A; Brix = B; Pol = C; dan Bobot batang $=\mathrm{D})$

Pengaruh intensitas serangan hama kutu perisai terhadap penurunan hasil telah ditetapkan dalam empat indikator (bobot batang, pol, brix, dan rendemen). Hasil pengamatan menunjukkan bahwa intensitas serangan hama kutu perisai pada batang tebu bervariasi, dari serangan ringan sampai berat (serius). Secara umum, semakin berat serangan hama kutu perisai, produksi tanaman tebu (yang dinyatakan dalam bobot batang, pol, brix, dan rendemen) semakin menurun (Gambar 2). Rendahnya kualitas (pol, brix, dan rendemen) dan kuantitas (bobot batang) hasil tanaman tebu akibat serangan hama kutu perisai kemungkinan diakibatkan oleh perilaku makan kutu perisai yang menyukai bagian batang tebu. Kutu perisai menusukkan stiletnya pada sel penyimpan sukrosa atau parenkima. Stilet kutu dapat dipindahkan dari satu sel ke sel parenkima lainnya secara lateral sehingga jumlah tusukan menjadi banyak. Akibat tusukan kutu, sel tanaman menjadi rusak yang mengakibatkan menurunnya kandungan gula.

\section{SIMPULAN}

Perkembangan populasi kutu perisai $A$. tegalensis di pertanaman tebu PT GMP mulai 
meningkat pada tanaman tebu berumur 8 bulan (sekitar 50 ekor/batang) dan mencapai puncaknya (300 ekor/batang) pada tanaman berumur 11 bulan (tanaman mulai masak). Rata-rata kepadatan populasi kutu perisai selama satu musim tanam sekitar 100 ekor/batang.

Luas serangan kutu perisai pada pertanaman tebu di PT GMP semakin tahun semakin meningkat. Pada tahun 2001, luas serangan mencapai 1157, 95 ha (tujuh kali lipat dibandingkan dengan tahun 2000). Tingkat serangan tersebut juga mempengaruhi penurunan hasil (yang dinyatakan dengan bobot batang, pol, brix, dan rendemen). Penurunan hasil yang terbesar terjadi pada batang tebu yang terserang berat. Hasil ini membuktikan bahwa serangan kutu perisai pada pertanaman tebu dapat menurunkan kuantitas dan kualitas hasil tanaman tebu.

\section{DAFTAR PUSTAKA}

Box, H. E. 1953. List of Sugarcane Insects. CIE, London.
Hill, D.S. \& J. M. Waller. 1994. Pests and Diseases of Tropical Crops. Longman, London.

Long, W. H. \& S. D. Hensley. 1972. Insect pests of sugarcane. Ann. Rev. Entomol. 17: 149-176.

R \& D PT GMP. 2001. Kutu perisai (Aulacaspis tegalensis Zehnt.:Diaspididae). Publikasi Intern Research and Development PT Gunung Madu Plantations.

Rao, V.P \& T. Sankaran. 1969. Pest of Sugarcane . (J.R. Williams et al., ed.). Elsevier, Amsterdam.

Samoedi, D. 1993. Hama-Hama Penting Tebu di Indonesia. P3GI, Pasuruan.

Williams, J.R.. 1970. Studies on the biology, ecology and economic importance of the sugarcane scale insects Aulacaspis tegalensis (Zhnt) (Diaspididae) in Mauritius. MSIRA, Reduit, Mauritius. Bull. Ent. Res. 60: 61-95. 
Sunaryo \& R. Hasibuan: Perkembangan populasi kutu perisai di PT Gunung Madu Plantations

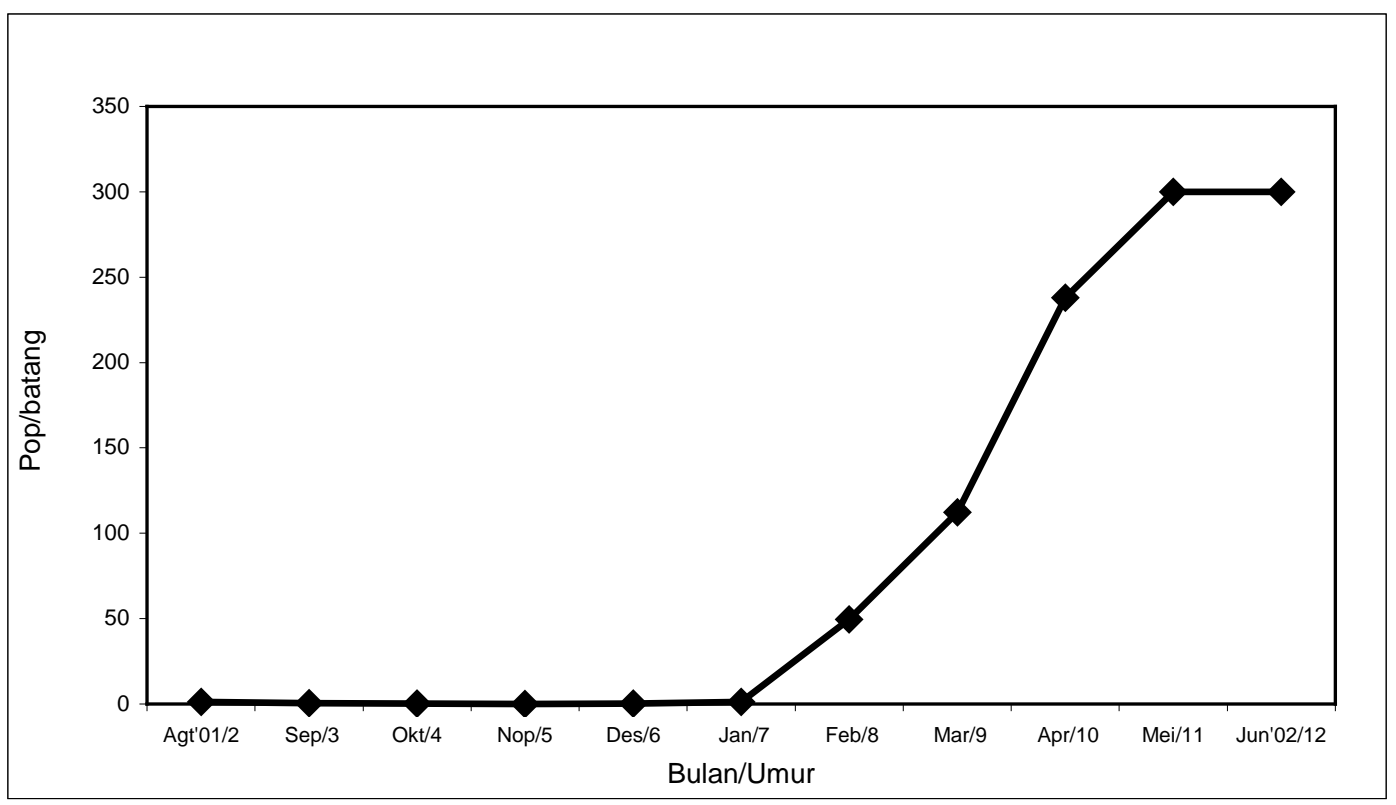

Gambar 1. Perkembangan populasi kutu perisai A. tegalensis pada tanaman tebu varietas GM21 di PT GMP 

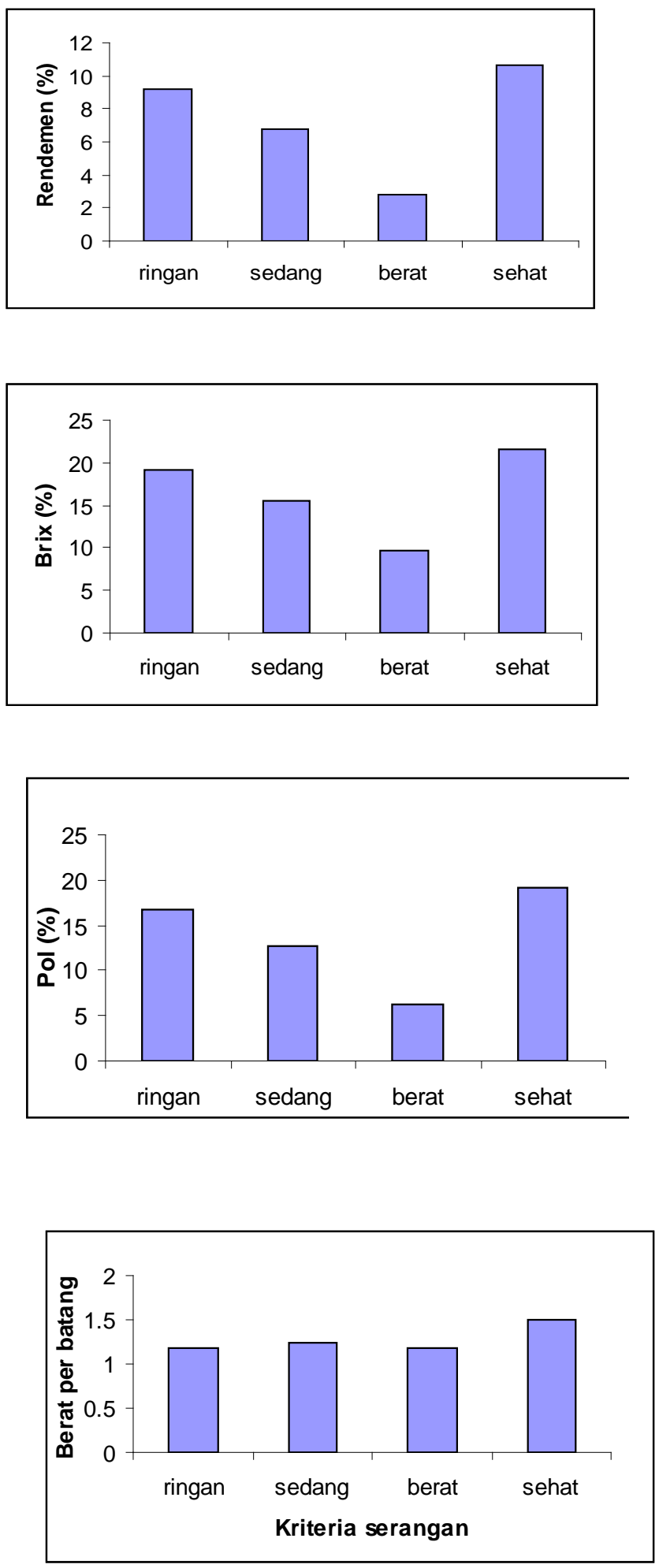

Gambar 2. Histogram tingkat serangan hama kutu perisai $A$. tegalensis pada indikator hasil tanaman tebu (berat per batang, persentase pol, brix, dan rendemen) 